\title{
Ética e o ensino do Direito Animal: estudo de caso
}

Ethics and the teaching of Animal Law: a case study

\author{
Heron José de Santana Gordilho* \\ Bruno Leal de Souza**
}

\begin{abstract}
RESUMO: O ensino sobre o Direito Animal não é nada fácil. Existem muitas barreiras a serem conquistadas, principalmente aquelas que se referem ao campo do comportamento humano, dos costumes, hábitos etc, além de "hábitos" da própria sociedade. Este estudo tem como objetivo analisar o desenvolvimento de uma ACCS Atividade Curricular e em Comunidade e Sociedade - disciplina optativa, de extensão, cujo nome é Ética e Direito Animal, da Faculdade de Direito da Universidade Federal da Bahia, por meio de um estudo de caso.
\end{abstract}

PALAVRAS-CHAVE: Ensino; Ética; Animal; Direito.

ABSTRACT: The teaching on Animal Rights is not easy. There are many barriers to be achieved, particularly those related to the field of human behavior, habits, etc., and "habits" of society itself. This study aims to analyze the development of ACCS - Curricular Activity and Community and Society - subject, which is optional and considered an extension, entitled Ethics and Animal Law, Federal University of Bahia Law School, through a case study.

KEYWORDS: Teaching; ethics; animal; Right.

\section{INTRODUÇÃO}

É preciso, inicialmente, ter em conta que o Direito sempre considerou os animais coisas suscetíveis de apropriação e comercialização, mesmo porque, diariamente, milhares deles são capturados e mortos no comercio legal ou clandestino (GORDILHO, 2010). Quebrar a barreira, com referência ao direito de vida dos animais, para que a população, e os próprios estudantes, percebam a relevância dos assuntos discutidos na atualidade não é tão fácil. E, isto acontece porque, quando a pessoa nasce já encontra um modo se "ser" e agir predeterminado; e, por ainda estar na sua fase de conhecimento daquilo que existe para que comece a ter uma

\footnotetext{
* Pós-Doutor pela Pace University Law School, New York (EU), onde integra a diretoria do Brazil-American Institute for Law and Environment (BAILE). Doutor em Direito pela Universidade Federal de Pernambuco (UFPE). Professor Associado das Faculdades de Direito da Universidade Católica do Salvador (UCSAL) e da Universidade Federal da Bahia (UFBA). Coordenador do Programa de Pós-Graduação em Direito da UFBA. Professor do Mestrado em Direito Animal e Sociedade da Universidade Autônoma de Barcelona (ESP). Presidente da Associación Latinoamericana de Derecho Animal (ALDA). Promotor de Justiça do Meio Ambiente na comarca de Salvador (MP/BA). E-mail: heron@ufba.br.

** Bacharelando Interdisciplinar em Saúde da UFBA, Bacharelando em Administração Hospitalar da UNOPAR, Licenciando em Matemática da UNINTER e Pesquisador do Núcleo Interdisciplinar de Pesquisa e Extensão em Direito dos Animais, Meio Ambiente e Pós-Modernidade da UFBA. E-mail: bruno.leal@ufba.br/ brunoleals@hotmail.com.br.

Data de recebimento do artigo: 10/01/2016 - Data de avaliação: 04/02/2016 e 09/02/2016.
} 
posição critica sobre aquilo que acontece, a pessoa humana segue os mesmos preceitos sociais que, no caso, é o não pensamento a respeito do direito de vida dos animais que se perpetua na cultura brasileira.

Para Durkheim, as pessoas, ao nascerem, encontram prontas as regras sociais, as normas de convivência, as tradições e as relações sociais, assim como os valores e as crenças (MELO, 2012) e quebrar ou rediscutir esse aprendizado anos após se ter consciência do que acontece é muito complicado, talvez pela falta de interesse no assunto, ou até mesmo pela inacessibilidade de informações.

Segundo o educador Paulo Freire (2013), conhecer é tarefa de sujeitos, não de objetos. E é como sujeito, e somente na qualidade de sujeito, que o homem realmente pode conhecer. Para o autor, só aprende verdadeiramente aquele que se apropria do apreendido, aquele que é capaz de aplicar o aprendido-apreendido a situações existenciais concretas (FREIRE, 2013). Em outras palavras, os que lidam com a vida cotidiana possuem uma grande capacidade de entender aquilo que está ao redor e, com isso, possibilitar a melhoria, mudança ou inibição de determinadas ações do cotidiano. Nenhum objeto seria capaz de entender os acontecimentos da vida, pois estes não possuem vida, são concretos e inertes, ao contrário dos seres humanos e animais, que conseguem perceber comportamentos, manifestações e sentimentos do dia a dia, como a dor (SINGER, 2004).

Singer (2004) traz um bom exemplo que ajuda a se impulsionar o pensamento, referente ao comportamento humano ante os animais que, todavia, foi o objeto de estudo da disciplina do estudo de caso a seguir. O exemplo, entretanto, foi o de que:

[...] as mulheres têm direito de votar, pois são tão capazes de tomar decisões racionais sobre o futuro quanto os homens. Cães, por outro lado, são incapazes de compreender o significado de votar, portanto, não pode ter o direito de votar. Há várias semelhanças óbvias entre homens e mulheres, ao passo que seres humanos e animais diferem bastante. Por conseguinte, seria possível afirmar: homens e mulheres são seres semelhantes e devem ter direitos semelhantes, enquanto seres humanos e não-humanos são diferentes e seus direitos não devem ser iguais (SINGER, 2004).

O exemplo mencionado por Singer permite dar início a uma grande questão: os animais não compreendem o significado do voto porque não querem votar ou porque não possuem, na sua "formação" coletiva, um entendimento para tal? A Constituição Federal Brasileira de 1988, em seu Art. ${ }^{\circ} 14$ expressa que, a soberania popular será exercida pelo sufrágio universal e pelo voto direto e secreto [...]. Logo, se o voto foi instituído para possibilitar a democracia na escolha de determinadas "coisas" (como eleições e outros) no País, sendo então uma 
criação social do ser humano para construir e harmonizar um ambiente coletivo sendo que essa elaboração se dá em sociedade com as outras pessoas (MELO, 2012), por que os animais, não humanos, como cita o autor, deveriam ter consciência desse ato, que porventura não é de sua criação?

É notório o fato de que a linguagem entre humanos e animais não é a mesma, pois há que se chamar de capacidade de fala que os animais não possuem. E, então, como se pode estabelecer uma ponte de contato entre esses seres, que também habitam o Planeta? Será que as ações humanas podem interferir no seu direito de vida, no seu direito de andar pelo mundo livremente? Se os humanos e os não humanos possuem direitos diferenciados, como relata Singer em seu exemplo, qual seria então a diferença entre esses direitos? Um dos direitos dos seres não humanos, que deveria ser instituído pelos entes humanos, não seria a proteção daquilo que os humanos, ao decidirem viver em sociedade, criaram, de forma que não afetasse o direito de vida dos animais?

Pelo mesmo motivo em que a ação é o objeto de ensaios da Ética, far-se-á um comparativo das ações, mesmo que indiretas, do ensino do Direito no viés do Direito Animal, por via de um estudo de caso, para que, nele, se possam perceber as condutas tidas por estudantes no ensino de um assunto que emerge no país, que é o Direito Animal. E, em paralelo ao estudo, demandar-se-ão soluções que possibilitem a compreensão do comportamento humano perante animais na tentativa de buscar explicações que viabilizem melhor inserção da ideia de Direito Animal na sociedade.

\section{NOÇÕES SOBRE ÉTICA}

Nota-se, na atualidade, o fato de ser necessário o estudo do comportamento humano, principalmente no que se refere ao campo da Ética, sobretudo porque diz respeito à experiência cotidiana, conduzindo a uma reflexão sobre os valores adotados, o sentido dos atos que se praticam e a maneira pela qual tomam decisões e se assumem responsabilidades. (MARCONDES, 2007).

É em suporte numa reflexão sobre as ações de cada qual que se podem perceber as consequências, sejam elas positivas ou negativas, e, por consequência, se poderá determinar se esta foi ou não uma boa conduta; já que, segundo Marcondes (2007), a problemática da Ética, portanto, em amplo sentido, diz respeito à determinação do que é certo ou errado, bom ou mau, permitido ou proibido, de acordo com um conjunto de normas ou valores adotados 
historicamente por uma sociedade. A Ética "tenta" determinar a validade, num sentido positivo ou negativo, de uma determinada conduta perante o desenvolvimento dos comportamentos de certa sociedade no decorrer do processo histórico, que pode ou não aceitar o fato ocorrido com base nos seus costumes, modos de vida e maneira de agir.

Alguns autores, como Marcondes (2007), definem Ética como uma teoria ou ciência do comportamento moral dos homens em sociedade. É a ciência, pois, de uma forma específica de comportamento humano. O autor reforça, ainda, a noção de que a Ética é uma ciência da Moral, isto é, de uma esfera do comportamento humano. No dicionário Amora (2009), a ética é definida como um ramo da Filosofia que se dedica ao estudo dos valores morais da conduta humana. Outros autores, como Alencastro (2013), trazem uma definição de Ética um pouco mais simplificada. Segundo ele, a Ética é, portanto, teoria. Seja como ciência do comportamento ou como reflexão filosófica da Moral, ela tem como objeto de estudo um determinado tipo de costumes, cujas normas são interiorizadas por socialização e coletivamente aceitas numa dada sociedade.

Com os conceitos ora citados, percebe-se que o objeto da Ética são as ações humanas, os hábitos, costumes e até mesmo regras e leis que regem determinada sociedade (ALENCASTRO, 2013). E, pode-se notar, analisando os fragmentos dos autores, que, a Ética estuda o comportamento humano de cada sociedade, tendo como base os marcos históricos e as interações sociais das pessoas com o corpo social.

Já o Direito é uma fração de todo o estudo da Ética, uma vez que se percebe o seu aparecimento na tentativa de modelagem do comportamento no meio social, balizada pelas normas, leis e códigos sociais, que prescrevem certas condutas de um indivíduo em uma sociedade. E, se a Ética estuda a conduta humana, e porventura a lei também busca "modelar" certos comportamentos havidos por seres humanos, percebe-se que o campo do Direito está diretamente ligado à Ética, sendo esta um terreno mais amplo que o Direito, já que este trabalha com uma parte do comportamento regido por normas de conduta e aquela não estuda todo o tipo de comportamento.

Ao se falar de Ética, não se pode esquecer a Moral, uma vez que ela é o conjunto de hábitos e costumes efetivamente vivenciado por um grupo humano (SANTOS 1997 apud ALENCASTRO, 2013). E, pelo fato de a Moral ser um conjunto de ações desenvolvidas pelo indivíduo, é lícito dizer que a Moral está mais próxima do campo do Direito, já que a lei é aquele conjunto de hábitos e costumes considerados fundamentais e indispensáveis a sociedade, ou seja, acordos de caráter obrigatório estabelecidos entre pessoas de um grupo, 
para garantir justiça mínima, ou direitos mínimos de ser (SANTOS 1997 apud ALENCASTRO 2013). Logo, com isso, é notório o fato de que a Ética é instância geral e teórica capaz de promover a reflexão e a critica em relação às ações humanas (ALENCASTRO, 2013), ao passo que a Moral e o Direito são as próprias ações em si, em outras palavras, é a ação que porventura é o objeto de estudo da Ética.

Pelo mesmo motivo que a ação é o objeto para estudar a Ética, será feito um comparativo das ações, mesmo que indiretas, do ensino do Direito no viés do Direito Animal mediante um estudo de caso, para que, nele, se percebam as condutas tidas por estudantes no ensino de um assunto que em curso no País, que é o Direito Animal.

\section{ESTUDO DE CASO}

O estudo em tela tem como objetivo analisar o desenvolvimento de uma ACCS Atividade Curricular e em Comunidade e Sociedade - disciplina optativa, de extensão, cujo nome é Ética e Direito Animal, da Faculdade de Direito da Universidade Federal da Bahia. Como forma de explicar a todas as pessoas o significado desta disciplina de extensão, a Universidade Federal da Bahia (2014, p. 108) publica, em seu Manual de Extensão Universitária, que:

\footnotetext{
A Atividade Curricular em Comunidade e em Sociedade (ACCS) é um componente curricular, modalidade "disciplina" de cursos de Graduação e Pós-Graduação, em que estudantes e professores da UFBA, em relação multidirecional com os grupos da sociedade, desenvolvem ações de extensão no âmbito da criação, tecnologia e inovação, promovendo o intercâmbio, a reelaboração e a produção de conhecimentos sobre a realidade com perspectiva de transformação.
}

O estudo foi realizado após o término da disciplina, que se desenvolveu no segundo semestre do ano de 2014, e como objeto de estudo foram analisados os diários de campo dos discentes, para que se pudesse notar a importância desta atividade em comunidade no desenvolvimento crítico dos discentes a respeito das realidades em que se inseriram no tempo.

O diário de campo foi a atividade avaliativa proposta para a disciplina, em que os alunos deveriam contar as experiências, além de criticas, questionamentos e outros, tida no decorrer dos 17 da disciplina no semestre. Cada dia possuía uma carga de quatro horas, o que proporciona ao discente uma maior inserção na realidade presenciada, potencializando sua capacidade de critica, ao perceber se existem inconformidades entre aquilo que deveria ser feito com aquilo que está sendo feito. 
Logo no início do semestre, havia 29 discentes matriculados no componente curricular, porém, ocorreram 6 desistências no decorrer do curso e, no final, três deles perderam por ultrapassar o máximo de faltas permitido, o que poderia comprometer sua aprendizagem já que a vivência de um dia não poderia mais ser repetida. Consoante Jaegwon Kim (LECLERC, 2014), um evento é uma instanciação de uma propriedade por um objeto (que pode ser um agente) em um momento determinado. Logo, se a vivência de um determinado dia é um evento, com propriedades, que ocorreu num determinado tempo este não ocorrerá da mesma forma duas vezes.

Ao final do semestre, 13 dos 20 diários, referentes aos 20 discentes que frequentaram a atividade até o final sem perderem por falta de frequência ou desistência, foram entregues. E, dentre estes entregues, dez estavam dentro do período, enquanto três foram entregues após o período estipulado pela própria turma no primeiro encontro.

Dentre os diários cedidos, tentou-se estabelecer alguns parâmetros avaliativos para que se pudesse perceber o desenvolvimento crítico dos discentes: a quantidade de textos juntada ao diário, se houve descrição, opinião, argumentos que validassem seu posicionamento, exemplos, plágio, se foi registrado mero resumo dos acontecimentos vivenciados, se as citações foram referenciadas ou não e se os textos necessitavam de debates que o complementassem.

Dentre todos os diários, somente 13 foram estudados neste artigo, uma vez que os três diários entregues fora do prazo foram escritos de ultima hora e em texto corrido, o que impossibilitava uma comparação com os demais que estavam no prazo.

Entre os 13 diários entregues, havia alguns incompletos, uma vez que houve 17 dias de aulas distribuídos nos cinco meses letivos, sendo uma aula cada semana. E, pela lógica, calculando a quantidade de dias e de textos a serem produzidos pelos discentes, dever-se-ia receber um total de 169 textos dos 13 discentes que tiveram seus diários aqui analisados. Esta quantidade de textos teve como base o cálculo feito pela multiplicação entre a quantidade de dias vezes o total de discentes, no caso, 17 vezes 13, que é igual a 169 textos. Apenas foram apresentados, todavia, 155 textos, faltando um total de 14 textos.

Após a contabilização dos escritos e depois da tabulação dos dados de cada um, foi possível notar que dos 155 , apenas 101 , que representavam cerca de $65,16 \%$, descreveram as vivências de cada encontro com a comunidade e reuniões, enquanto 54 textos, que representavam a parcela de $34,84 \%$, não descreveram o que ocorreu, apenas citaram alguns 
acontecimentos e logo foram tomando posições críticas sobre as vivências, enquanto a maior parcela optou pelo enfoque da descrição de cada acontecimento do dia.

Há, ainda, um percentual parecido com o citado há pouco, onde 104 dos 51 textos exprimirão opiniões e posicionamentos sobre suas vivências. É notório que a parcela de $67,10 \%$ expressou críticas e posicionamentos sobre as experiências obtidas no decorrer da disciplina, enquanto $32,90 \%$ dos discentes preferiram apenas descrever os fatos dos encontros. Além disso, observou-se também que, praticamente, metade dos textos apresentados (cerca de 49,68\%) justificou sua opinião ou posicionamento, enquanto os demais textos, 50,32\%, preferiram apenas descrever o ocorrido ou dar uma opinião sobre sua vivência, enquanto outros foram além de um simples posicionamento do que vivenciaram. E, como se nota, cerca de 45,16\% dos textos exprimiram exemplificações, enquanto o restante dos textos, 85 , representativos de $54,84 \%$ do montante, preferiram não dar exemplos daquilo que escreviam.

Foi verificado que em nenhum dos diários houve plágio ou qualquer cópia indevida da internet; todos os textos foram realmente escritos pelos estudantes. $\mathrm{Na}$ escrita de seus diários, entretanto, foram detectadas algumas citações referenciadas, cerca de $20 \%$, e, em $80 \%$ não houve as devidas referenciações.

Cerca de 117 textos analisados foram percebidos com uma grande quantidade de resumos. Em outras palavras, foram encontradas muitas citações como forma de resumir aquilo que vivenciaram e, com isso, cerca de $81,29 \%$ dos textos apresentados, o equivalente a 126 textos, necessitavam de mais discussões para que pudessem relatar mais sobre aquilo que vivenciaram em cada encontro, principalmente, com a comunidade.

Percebe-se que entre os 13 diários analisados, há média de cerca de 7,8 textos que possuem a presença de descrição, enquanto há a presença de 4,2 textos que não possuem descrições do que aconteceram em cada encontro.

Verificou-se, ainda, que em 13 textos presentes em cada diário, cerca de 8 possuíam opiniões sobre as vivências e aproximadamente 5 textos apenas continham as descrições detalhadas do que ocorreram no dia a dia da disciplina.

Quanto menos os textos eram descritos, havia opiniões em quase todos eles e, além disso, tinha-se mais a presença de justificações daquilo que se opinava e mais exemplos eram citados, o que acarretava baixa necessidade de discussões por haver um posicionamento justificado daquilo que se vivenciou. Em contrapartida, pode-se perceber que quanto mais os discentes descreviam passo a passo o que ocorreu na sua vivência, opinavam, mas não 
justificavam seus posicionamentos e, com isso, menos exemplos eram dados e mais se necessitavam de uma discussão em seus textos, uma vez que praticamente só escreviam o que ocorreu no dia, sem nenhuma, ou quase nenhuma, experiência, questionamento, dúvida ou quaisquer outro posicionamento sobre a visão de sua vivência.

Além disso, foi possível inferir que ao multiplicar 4,2, que é a média de textos com posicionamentos seguidos de justificativa e exemplificação, pelo número 13, que significa o total de diários entregues, ter-se-á um total de 55 textos. Ou seja, do total de 155 textos entregues, 55 textos foram considerados como completos em discussão por conter posicionamentos e justificativas sobre as vivências proporcionadas pela Atividade Curricular em Comunidade e em Sociedade.

Outro dado importante é o fato de que apenas três textos de cada diário apontavam alguma citação com referenciação ao seu autor, enquanto, aproximadamente, 5 em cada 13 textos apresentavam citações sem as devidas referenciações. Todavia, vale ressaltar que as citações apareciam nos textos como formas de exemplificação.

Outro indicativo a ser alvo de menção é o fato de que 75,48\% dos diários que mostrava uma predominância maior de resumos necessitavam de discussões acerca do que foi vivenciado. Enquanto isso, aqueles que não resumiram, 24,52\% dos textos, possuíam uma tendência de não haver necessidade de mais discussões. Isso não impossibilitava, no entanto, de proporem mais argumentos. Quanto maior a prevalência de resumos dos acontecimentos vividos, pelos próprios discentes em seus textos, maiores eram as necessidades de mais discussões e, quanto menor a prevalência de resumos, menores eram as necessidades de incidências de mais discussões sobre os fatos vivenciados.

\section{CONCLUSÃO}

A Atividade Curricular em Comunidade e Sociedade (ACCS) é uma das formas que a Universidade encontra para aproximar os estudos, e aquilo que é produzido pelas suas faculdades, da vivência cotidiana nas comunidades. Essa aproximação possibilita que os discentes percebam que nem sempre a teoria estudada esta aplicada e, nela, pode haver muitas distorções daquilo que se estuda. E esta junção entre teoria e prática visa a um aprendizado critico, onde há a possibilidade de investigar o porquê dos problemas existentes e das dificuldades e facilidades encontradas nesses caminhos. 
Vivenciar a realidade é perceber, com os próprios olhos, sentir na própria pele, a realidade que ora se estuda em um estado de "perfeição" na universidade e que ora se vivencia, mas não se dá as devidas atenções a essas diferenças. A experiência de vivenciar a realidade vai além do imaginário, ultrapassa as fronteiras que se possui quando apenas se leem os assuntos ligados ao objeto de estudo. Poder ver a ação acontecer é o mesmo que abrir portas e semear fronteiras para distintos conhecimentos que podem e vão enriquecer mais a vida, seja ela profissional ou não.

Analisando os diários de campo dos discentes do estudo de caso, contudo, notou-se que muitos deles, perto de 70\%, apenas fizeram seus diários por fazer, para cumprir tabela, apenas no intuito de poder obter a nota da atividade para que seu escore ou placar geral da faculdade não diminua. Tem-se, então, um interesse maior por números que, com certeza, vão demonstrar que o discente é melhor do que outros, do que com o conteúdo e a proposta da atividade, que é a percepção e desenvolvimento da crítica por meio das vivências.

Muitos dos textos escritos pelos discentes continham uma reprodução daquilo que se discutiu em sala e, com isso, pode-se pensar que essa reprodução ocorreu pelo fato de não quererem opinar ou discutir os casos abordados, apenas pensando em cumprir a atividade de maneira a obter a nota final, ou talvez para não acharem que suas opiniões são irrelevantes e supérfluas. Alguns textos até exprimiam algumas opiniões ou citações como forma de não deixar somente uma breve descrição do que ocorreu no encontro, podendo-se dizer que deu o “jeitinho" brasileiro, como diz DaMatta (1986), para que se pudesse perceber que houve uma critica sobre o ocorrido/observado. A omissão do debate, porém, em quase todos os textos pode comprovar, ou comprova, que os discentes não querem discutir sobre o assunto. Levouse, ainda, em conta que a falta de discussões pode ser causada pelo primeiro contato com o assunto ou pela desmotivação relativa aos debates, ou até pelo modo como eram guiados.

Como, porém, o assunto Direito Animal é emergente, não havendo muitas décadas de debates, convém propor maneiras atrativas e que chamem a atenção dos espectadores, pois discutir assuntos com modo tradicional de ensino pode não estar mais despertando o interesse dos discentes, o que levam a buscar outros assuntos mais interativos. Outro ponto importante a ser destacado é que, quanto mais o assunto em discussão se aproxima da realidade daqueles que ouvem, mais rápido se poderá despertar a atenção e interesse para o que está sendo abordado. Nas discussões, deve-se ser simples, objetivos e inovadores, pois, assim, se logrará fazer com que o outro perceba a relevância da discussão. 
O que se sente, dia a dia, com maior força aqui, menos ali, em qualquer dos lados em que o mundo se divide, é um homem simples esmagado, diminuído e acomodado, convertido em espectador, dirigido pelo poder dos mitos que forças sociais poderosas criam para ele (FREIRE, 2014). As pessoas têm para si que é mais fácil resignar-se do que levantar-se contra as forças que as mantém inertes, e se pode perceber isso quando se analisam os diários e se percebem que quase não há opiniões ou posicionamentos sobre o que acontece. Freire (2014) ainda complementa, exprimindo a ideia de que a pessoa sem a capacidade de visualizar esta tragédia, de captar criticamente seus temas, de conhecer para interferir, é levada pelo jogo das próprias mudanças e manipulada pelas já referidas prescrições que lhes são impostas.

Em outras palavras, precisa-se, primeiramente, proporcionar ao indivíduo o início de uma conscientização crítica sobre a sua vivência. Isso se dará, todavia, com base em discussões ligadas ao seu contexto mais próximo, e não distante, para que ele possa começar a perceber que, assim como uma só palavra pode possuir múltiplos significados, uma intenção é passível de conduzir a diversos caminhos, intimamente atrelados ao seu comportamento diante do meio social.

\section{REFERÊNCIAS}

ALENCASTRO, Mário Sergio Cunha. Ética empresarial na prática: liderança, gestão e responsabilidade corporativa. Curitiba: InterSaberes, 2013.

AMORA, Antônio Soares. Minidicionário Soares Amora da língua portuguesa. 19. ed. São Paulo: Saraiva, 2009.

BRASIL. Constituição Federativa do Brasil de 1988. 26. ed. Brasília: Câmara dos Deputados, Coordenação de Publicações, 2006.

DAMATTA, Roberto. O que faz o Brasil, Brasil? Rio de Janeiro: Rocco, 1986.

FERRAZ JUNIOR, Tercio Sampaio. Introdução ao estudo do direito: técnica, decisão, dominação. 3. ed. São Paulo: Atlas, 2001.

FREIRE, Paulo. Extensão ou comunicação? Tradução Rosiska Darcy de Oliveira. 16. ed. Rio de Janeiro: Paz e Terra, 2013.

Educação como prática da liberdade. 36. ed. ver atual. São Paulo: Paz e Terra, 2014

GORDILHO, Heron José de Santana. Direito Ambiental pós-moderno. Curitiba: Juruá, 2010. 
Heron José de Santana. Abolicionismo animal. Salvador: Evolução, 2008.

MELO, Alessandro de. Fundamentos socioculturais da educação. Curitiba: InterSaberes, 2012. (Série Fundamentos da Educação).

REGAN, Tom. Jaulas vazias: encarando o desafio dos direitos animais. Porto Alegre, RS: Lugano, 2006.

SINGER, Peter. Libertação animal. Porto Alegre, São Paulo: Lugano, 2004.

TORRES, João Carlos Brum (org.). Manual de Ética: questões de ética teórica e aplicada. Petrópolis, RJ: Vozes; Caixa do Sul, RS; Universidade de Caxias do Sul; Rio de Janeiro: BNDES, 2014.

UNIVERSIDADE FEDERAL DA BAHIA. Pró-Reitoria de Extensão Universitária. Manual de extensão universitária da UFBA. Salvador: UFBA, 2014. 